\title{
Renal calcification in preterm infants: follow up at 4-5 years
}

\author{
C A Jones, S King, N J Shaw, B A Judd
}

\begin{abstract}
Aim-To determine the consequences of renal calcification in preterm infants.

Methods-A cohort of 11 preterm babies was studied at the age of 4 to 5 years. They had had renal calcification as neonates. Seventeen matched controls were also studied. Each child had a renal ultrasound scan, a calcium load test, and a desmopressin test for renal concentrating ability (RCA). The study group also had glomerular filtration rate (GFR) estimated, using the height:creatinine ratio, and tubular phosphate reabsorption, without phosphate load, per glomerular filtration rate ( $T p / G F R)$ calculated.

Results-In the study group the median GFR was $61 \mathrm{ml} / \mathrm{min} / 1.73 \mathrm{~m}^{2}$ (range $46-79$ $\mathrm{ml} / \mathrm{min} / 1.73 \mathrm{~m}^{2}$ ) and the median calculated Tp/GFR SD score was $\mathbf{- 0 . 9 4}$ (range $-\mathbf{2 . 8}$ $0.68)$. Five children out of the study group had ultrasonic evidence of renal calcification. There was no significant difference between the two groups in renal size, calciuria, before or after calcium load, or RCA. Eight children (three patients, five controls) had an abnormal calcium load test. The RCA of the children in the study and control groups combined was below that of published values, with a median calculated SD score $-0.71(95 \%$ CI -1.21 to -0.23).

Conclusions-There was evidence of renal dysfunction in children who had been born preterm. Renal calcification detected in the neonatal period does not seem to be a major predisposing factor for the abnormalities of renal function subsequently observed in these infants.

(Arch Dis Child 1997;76:F185-F189)
\end{abstract}

Keywords: renal calcification; glomerular filtration rate; tubular phosphate reabsorption

Renal calcification was first reported in preterm infants in $1982 .{ }^{1}$ Its presence has been linked to frusemide treatment and hypercalciuria, ${ }^{2}{ }^{3}$ and to an inappropriate dietary calcium:phosphate ratio. ${ }^{45}$ Other associations suggested have been the use of dexamethasone ${ }^{6}$ or xanthines, ${ }^{7}$ poor urinary flow rate, alterations in urinary $\mathrm{pH}$ and a decrease in the urinary concentrations of inhibitors to crystal formation. ${ }^{8}$ More recently, an increase in the urinary calcium oxalate saturation observed in neonates receiving total parenteral nutrition was shown to be associated with nephrocalcinosis. ${ }^{9}$ Jacinto et $a l^{10}$ and Short and Cooke ${ }^{11}$ have shown that the smallest and most immature preterm infants are more likely to develop renal calcifications. In the latter study multivariate analysis showed that duration of oxygen treatment was the strongest clinical indicator of calcification. Acute complications related to renal calcification may be urinary tract infections, abdominal pain, and haematuria.

Short term complications include renal glomerular and tubular dysfunction. Downing et al showed that preterm infants, aged 1 to 2 years, who had developed renal calcifications, had decreased tubular function when compared with preterm infants who had not developed renal calcifications. ${ }^{12}$ Ezzedeen et al reviewed nine preterm infants aged 9 to 56 months, who had renal calcification in the newborn period, and found that the serum creatinine and calculated glomerular filtration rates were abnormal in four of them. ${ }^{2}$

The aim of this study was to determine the presence of medium term renal complications in children aged 4 to 5 years, who had developed renal calcification in the neonatal period.

\section{Methods}

In a study performed at Liverpool Maternity Hospital in 198921 preterm infants were found to have renal calcification. ${ }^{11}$ Renal calcification was identified by sonography, using strict criteria. ${ }^{13}$ Five of these infants later died. The remaining 16 children were invited to take part in the present study. The parents of three children declined to take part and two other children were untraceable. The remaining 11 children, who had ultrasonic evidence of renal calcification in the neonatal period, constituted the study group. These were matched for sex, birthweight, gestational age and chronological age with 17 controls from the same original study, who did not have renal calcification as neonates.

Both the study group and the control group had a renal ultrasound scan, a calcium load test, an intranasal desmopressin test and urinalysis. The renal ultrasound scan used an Ultra Mark 9 high definition imaging ultrasound machine (Advanced Technical Laboratories, Seattle, USA), with a $3.5 \mathrm{mHz}$ curvilinear transducer and a linear $10.5 \mathrm{mHz}$ transducer, to measure renal length and identify the presence of renal calcification. This was identified if there were focal areas of hyperechogenicity visible in the renal medulla. These foci did not necessarily show acoustic shadowing. The ultrasound scans were per- 
Table 1 Demographic details of study group and controls

\begin{tabular}{lll}
\hline & Study group $(n=11)$ & Controls $(n=17)$ \\
\hline Percentage male & 36 & 35 \\
Median (range) birthweight $(\mathrm{g})$ & $850(580-1856)$ & $982(710-1760)$ \\
Median (range) gestational age (weeks) & $27(24-31)$ & $28(25-31)$ \\
Median (range) chronological age (months) & $56(49-61)$ & $54(52-61)$ \\
\hline
\end{tabular}

formed by a single experienced radiologist (SK), who had no knowledge of the child's ultrasound scan in the neonatal period.

The calcium load test was first described by $\mathrm{Pak}^{14}$ for the diagnosis of absorptive, resorptive, and renal hypercalciuria and was later modified for children. ${ }^{15}$ The children were fasted overnight but were allowed to drink clear fluids. The early morning urine was discarded after which a two hour urine collection was performed. One gram $/ 1.73 \mathrm{~m}^{2}$ of calcium, in the form of calcium sandoz, was given. A timed urine collection for two consecutive two hour periods was then performed. Each urine was analysed for calcium and creatinine and the urine sample with the highest calcium creatinine ratio following the calcium load was included in the results. A fasting urine calcium:creatinine ratio $>0.7 \mathrm{mmol} / \mathrm{mmol}$ or a post calcium load value $>1 \mathrm{mmol} / \mathrm{mmol}$ was considered to represent hypercalciuria. The children were not on a calcium or salt restricted diet before the calcium load test. A dietary history of what each child had eaten and drunk for three days before the calcium load test was recorded by the parents. The average daily intake of sodium and calcium for these three days were calculated using the Microdiet computer program based on McCance and Widdowson's Composition of Foods. ${ }^{16}$

An intranasal desmopressin test for tubular concentrating function was also performed. The children were asked to empty their bladder of any residual urine. The children were then given 20 mcg of 1-deamino-8-D-arginine vasopressin (DDAVP) intranasally. Two specimens of urine were collected between one and eight hours and the urine osmolality measured. The urine specimen with the maximum osmolality was taken as that which measured renal concentrating function. This value was then compared with the reference values for renal concentrating capacity. ${ }^{17}$

Urinalysis for proteinuria and haematuria was performed on an early morning urine sample. The urinary albumin:urinary creatinine ratio was measured on an aliquot of the early morning urine sample. Urinary albumin was measured by rate nephelometry.

Data were retrieved from the case notes on birthweight, gestation, days of supplemental oxygen, incidence of retinopathy of prematurity and intraventricular haemorrhage, and days receiving total parenteral nutrition. Infants were considered to be at risk of aminoglycoside nephrotoxicity if they had received a dose following a high trough concentration or if there was a documented high peak (gentamicin trough $>2 \mathrm{mcg} / \mathrm{ml}$ or peak $>10 \mathrm{mcg} / \mathrm{ml}$; vancomycin trough $>10 \mathrm{mcg} / \mathrm{ml}$ or peak two hours after start of infusion $>40 \mathrm{mcg} / \mathrm{ml}$ ). The number of such episodes was recorded.
Aminoglycoside concentrations had been taken at the third or fourth dose either after the start of treatment or if the dose was changed.

The parents were asked to complete a questionnaire. If there was a previous history of urinary tract infection the general practitioner or hospital notes were used to verify this. The study group also had the following investigations. (For ethical reasons blood was not taken from the control group.)

Plasma sodium, calcium, phosphate and creatinine were measured using a Technicon autoanalyser. Parathyroid hormone (PTH) was measured using an immunoradiometric assay recognising the intact molecule. At the same time as the plasma sample, urine was collected and analysed for creatinine, sodium, and phosphate.

Using these results, tubular phosphate reabsorption under basal conditions, without phosphate load, per glomerular filtration rate, was calculated as a measure of renal phosphate handling. ${ }^{18}$

$$
\mathrm{Tp} / \mathrm{GFR}=\mathrm{Sp}-\frac{\mathrm{Up} . \mathrm{Scr}}{\mathrm{Ucr}}
$$

where $\mathrm{Sp}=$ serum phosphate in $\mathrm{mmol} / \mathrm{l}, \mathrm{Up}=$ urinary phosphate in $\mathrm{mmol} / \mathrm{l}, \mathrm{Scr}=$ serum creatinine in $\mathrm{mmol} / \mathrm{l}, \mathrm{Ucr}=$ urinary creatinine in $\mathrm{mmol} / 1$

An estimate of creatinine clearance was calculated using the modified CounahanBarratt formula. ${ }^{19} 20$

$$
\mathrm{GFR}=\frac{40 \times \mathrm{ht}}{\mathrm{Pcr}}
$$

where $\mathrm{GFR}=$ glomerular filtration rate in $\mathrm{ml} / \mathrm{min} / 1.73 \mathrm{~m}^{2}$, ht=height in $\mathrm{cm}$, and $\mathrm{Pcr}=$ plasma creatinine concentration in $\mu \mathrm{mol} / 1$.

The study was approved by the local ethics committee.

Statistical analysis was performed using the Mann-Whitney $U$ test for continuous variables and the $\chi^{2}$ or Fisher's exact test using $2 \times 2$ tables for categorical variables.

\section{Results}

There was no significant difference between the median age, gestational age, birthweight and sex between the study group and the control group (table 1). Five out of 11 children, aged 4 to 5 years, in the study group had ultrasonic evidence of renal calcification. This was present in both kidneys in three of them. Renal calcification was not identified in any of the control group. An additional child in the study group had renal colic at the age of 3, secondary to a right sided ureteric calculus. An ultrasound scan at that time also showed calcification. A calcium load test indicated that this patient had absorptive hypercalciuria and she was then started on a low calcium diet. At the age of 5 her ultrasound scan was normal.

One child in the study group had only one kidney and another had a renal cyst in the upper pole of the left kidney. No structural renal abnormalities were found in the control group. Renal length was measured ultrasonically in each kidney and plotted against height, using a published reference range. ${ }^{21}$ Out of 55 
Table 2 Results of renal investigations performed on study and control group

\begin{tabular}{|c|c|c|c|}
\hline & $\begin{array}{l}\text { Study group } \\
(n=11)\end{array}$ & $\begin{array}{l}\text { Controls } \\
(n=17)\end{array}$ & Pvalue \\
\hline Renal calcification on ultrasonography & 5 & 0 & $<0.001$ \\
\hline No of kidney $<95 \%$ CI for length & 4 & 4 & NS \\
\hline $\begin{array}{l}\text { Median (range) pre-load calcium/creatinine } \\
(\mathrm{mmol} / \mathrm{mmol})\end{array}$ & $0.22(0.03-1.15)$ & $0.23(0-1.6)$ & NS \\
\hline $\begin{array}{l}\text { Median (range) post-load calcium/creatinine } \\
(\mathrm{mmol} / \mathrm{mmol})\end{array}$ & $0.6(0-1.3)$ & $0.32(0-1.65)$ & NS \\
\hline Median (range) osmolality (mosmol/kg) & $1022(646-1086)$ & $928(727-1247)$ & NS \\
\hline
\end{tabular}

kidneys, the lengths of eight were below the $95 \%$ confidence limits. In two children out of the study group the lengths of both kidneys were below the $95 \%$ confidence limits. Four children out of the control group had a small kidney on one side.

Urinalysis showed that there was neither blood nor protein in all the early morning urine samples. Two children had an albumin:creatinine ratio $>2.5 \mathrm{mg} / \mathrm{mmol}(3.9$ and 4.5 $\mathrm{mg} / \mathrm{mmol}$ ), indicating microalbuminuria. ${ }^{22}$

The results of the calcium load test and renal concentrating capacity after the administration of intranasal desmopressin are shown in table 2. There was no significant difference between the study group and the control group regarding urinary calcium:creatinine ratio before and after calcium load or maximum urine osmolality. Three children in the study group and five in the control group had an abnormal calcium load test. Four of these (two in the control and two in the study group) had a fasting urinary calcium:creatinine ratio $>0.7 \mathrm{mmol} / \mathrm{mmol}$, suggesting renal hypercalciuria, ${ }^{15}{ }^{23}$ and in three of these children (one in the control and two in the study group) the post load value was $>1$ $\mathrm{mmol} / \mathrm{mmol}$. Four children (one in the study group and three controls) had a fasting urinary calcium:creatinine ratio $<0.7 \mathrm{mmol} / \mathrm{mmol}$ and a post load value $>1 \mathrm{mmol} / \mathrm{mmol}$, suggesting absorptive hypercalciuria. ${ }^{15}$

The median value of the maximum urine osmolality in the study group was 1022 mosmol/kg (range 646-1086) and that in the control group was $928 \mathrm{mosmol} / \mathrm{kg}$ (range 727 1247). The mean value for normal children of this age has been reported to be $1062 \mathrm{mosmol} /$ $\mathrm{kg}$, with a range of $795(-2 \mathrm{SD})$ to 1330 (+2SD) mosmol/kg. ${ }^{17}$ The median maximum urine osmolality of both the study and the control groups was $973 \mathrm{mosmol} / \mathrm{kg}$ (95\% CI 888 to $1033 \mathrm{mosmol} / \mathrm{kg}$ ) with a corresponding median SD score of $-0.7(95 \% \mathrm{Cl}-1.21$ to -0.23) (fig 1).

In the study group the median estimated glomerular filtration rate was $61 \mathrm{ml} / \mathrm{min} /$ $1.73 \mathrm{~m}^{2}$ (range $46-79 \mathrm{ml} / \mathrm{min} / 1.73 \mathrm{~m}^{2}$ ), (published range of 89 to $\left.165 \mathrm{ml} / \mathrm{min} / 1.73 \mathrm{~m}^{2}\right) .^{24}$ The median Tp/GFR was 3.8 ; the published mean value for age is $4.4(\mathrm{SD} 0.6)^{18}$ and the

Table 3 Median and range of renal investigations on study group

\begin{tabular}{lccl}
\hline & Median & Range & Published reference range \\
\hline $\mathrm{GFR}\left(\mathrm{ml} / \mathrm{min} / 1.73 \mathrm{~m}^{2}\right)$ & 61 & $46-79$ & $89-165^{24}$ \\
$\mathrm{Tp} / \mathrm{GFR}$ & 3.8 & $2.7-4.8$ & $3.2-5.6^{18}$ \\
$\mathrm{SD} \mathrm{Tp} / \mathrm{GFR}$ & -0.94 & $-2.80-0.68$ & \\
$\mathrm{PTH}(\mathrm{pmol} / \mathrm{l})$ & 1.1 & $0.6-2.7$ & $1.1-3.5^{23}$ \\
\hline
\end{tabular}

$\mathrm{GFR}=$ glomerular filtration rate; $\mathrm{Tp} / \mathrm{GFR}=$ tubular phsophate reabsoption per GFR; $\mathrm{SD}=$ standard deviation; PTH = parathyroid hormone.

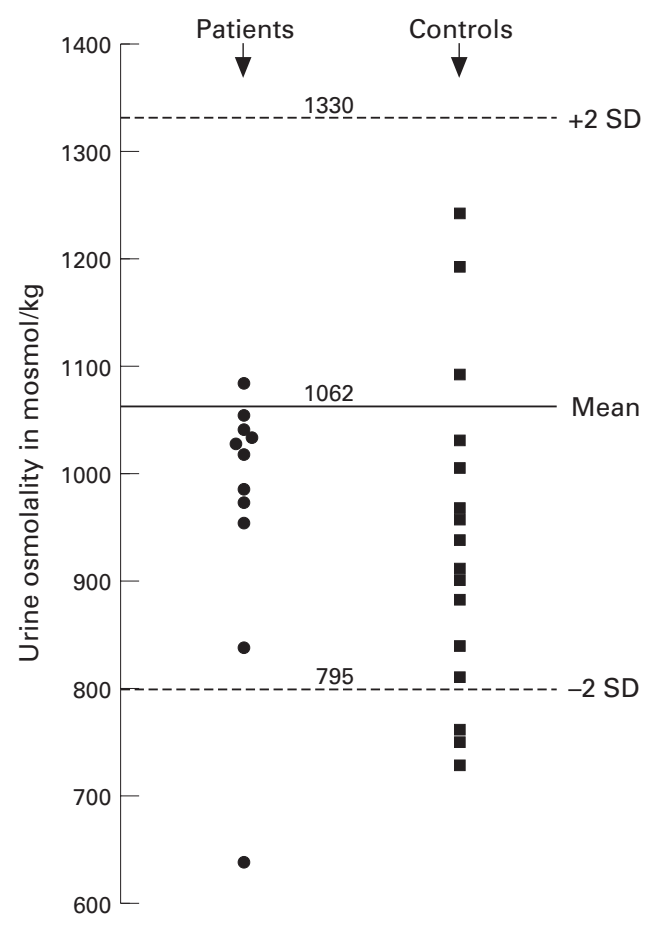

Figure 1 Renal concentrating ability after administration of $D D A V P$.

median calculated SD score for $\mathrm{Tp} / \mathrm{GFR}$ was -0.94 . Three children in the study group had a PTH value below the normal range. ${ }^{23}$ The serum values of calcium and phosphate were all within the normal range. These results are summarised in table 3.

There were no significant associations between decreased renal concentrating capacity or hypercalciuria and gestational age, birthweight, days of supplemental oxygen, retinopathy of prematurity or intraventricular haemorrhage. There was a trend towards those children who had idiopathic hypercalciuria to have received an aminoglycoside following a high trough concentration in the neonatal period, but this was not significant $(P=0.07$, Fisher's exact test).

In three children (two in the study group, one control) urinary tract infection had been confirmed on a midstream urine sample since discharge from the neonatal unit. In the two children from the study group this was associated with systemic upset but did not result in renal scarring on a subsequent dimercaptosuccinic acid technetium isotope (DMSA) scan.

\section{Discussion}

Few studies have looked at the short to medium term effects of renal calcification in children who were born preterm. Ezzedeen et al looked at nine children aged between 9 and 56 months, who had been identified as having renal calcification in the neonatal period. ${ }^{2}$ Sonography revealed complete resolution of renal calcification in four children and improved, but persisting, calcification in five children. One child had a small kidney on one side, and the serum creatinine and calculated GFR were abnormal in four. There were no controls in this study. 
In the study by Downing et al those children who had received frusemide and had developed renal calcifications had a significantly higher urinary calcium:creatinine ratio and fractional excretion of sodium compared with children who had not developed calcifications but had received frusemide. ${ }^{12}$ The first group also had a lower tubular reabsorption of phosphate and lower tubular acidification capacity. The average chronological age in this study was 14.1 months and some of the children would have been less than 12 months corrected age, when renal tubular and glomerular function are not yet mature. Renal calcification seems to diminish with increasing age. Downing et al suggested that as calcification improves renal function may also improve. We therefore felt that it was important to study a group of children aged 4 to 5 years old, who had been identified as having renal calcifications in the neonatal period.

In our study five out of 11 children, aged 4 to 5 years, had ultrasonic evidence of renal calcification. Ultrasound scanning is the most sensitive imaging technique for the detection of renal calcification ${ }^{13}$ and there is good correlation between ultrasound findings and histological evidence of nephrocalcinosis and nephrolithiasis. ${ }^{25}$ There was no clinical evidence of other pathological processes that might give rise to similar ultrasonic appearances. ${ }^{26}$ The patients classified as having renal calcification in the original study had areas of hyperechogenicity on at least two consecutive scans, performed at weekly intervals. ${ }^{11}$ The age at diagnosis of renal calcification ranged from 27 days to 66 days. Hyperechogenicity associated with renal insufficiency in the preterm infant usually occurs earlier than this and tends to be transient. ${ }^{27}$

Predicted GFR and Tp/GFR were reduced in some children from the study group. As blood was not taken from the control group it is uncertain whether prematurity or renal calcification was the predisposing factor for this.

Renal calcification in preterm neonates does not seem to affect subsequent renal calcium excretion or tubular concentrating ability, as there were no significant differences between the study and control groups. Twenty eight per cent of all the children (both study and control groups) had an abnormal calcium load test (four children had a fasting urinary calcium: creatinine ratio $>0.7 \mathrm{mmol} / \mathrm{mmol}$ and four children had a normal fasting urinary calcium: creatinine ratio but a post load value of $>1$ $\mathrm{mmol} / \mathrm{mmol}$ ). Five children from the control group had an abnormal calcium load test, which suggests that preterm infants may have an increased risk of developing idiopathic hypercalciuria that is not associated with renal calcification. Hypercalciuria is defined in children as a urinary calcium excretion greater than $4 \mathrm{mg} / \mathrm{kg} /$ day. ${ }^{28}$ Other authors have demonstrated a correlation between 24 hour urinary calcium and a urinary calcium:creatinine ratio on an overnight urine sample, ${ }^{29}$ or a second fasting urine after liquid intake. ${ }^{30}$ We did not measure calcium excretion on a 24 hour urine collection because of its unreliability in this age group. We chose the calcium load test. This involves a fasting urine sample and a urine collection following a calculated dose of calcium, because urinary calcium excretion is affected by dietary calcium. ${ }^{31}$ The upper reference limit for the second fasting urine sample was taken from a study measuring urinary calcium on a population of children from the North of England, who were eating a normal diet. ${ }^{23}$ The calcium load test may appear normal in children with hypercalciuria, defined by a 24 hour urinary calcium $>4 \mathrm{mg} / \mathrm{kg} / \mathrm{day}$, if they have low salt or restricted calcium intake before the test. $^{32}{ }^{33}$ An abnormal calcium load test in a child with a normal 24 hour urinary calcium has been described in a child with a history of renal colic and renal stones. ${ }^{34}$ We are not aware of other studies that have shown an abnormal calcium load test in children with normal urinary calcium on a 24 hour collection. It is therefore unlikely that we overestimated the number of patients with raised urinary calcium excretion. One child who was felt to have absorptive hypercalciuria developed a ureteric calculus and was placed on a low calcium diet.

Urinary calcium excretion parallels sodium excretion $^{31} 35$ and is affected by both dietary sodium and calcium. We did not find any difference in dietary sodium or calcium in the three days before the calcium load test between those children who had hypercalciuria and those who did not. The pathogenesis underlying idiopathic hypercalciuria is not yet fully understood. Several hypotheses have been suggested, including increased bone resorption ${ }^{36}$ and a disordered control of renal phosphate handling and $1,25(\mathrm{OH}) 2$ vitamin $\mathrm{D}$ production. ${ }^{37}$ Two children who had a $\mathrm{Tp} / \mathrm{GFR}<2 \mathrm{SD}$ also had raised urinary calcium excretion and in one of these children PTH was undetected. A further child in this group, who also had idiopathic hypercalciuria, had a SD Tp/GFR of -1.29 and a PTH value of 1 . Blood was not taken from the control population, so we cannot comment on renal phosphate handling in the five controls with raised calcium excretion.

One explanation of decreased phosphate reabsorption may be aminoglycoside induced nephrotoxicity which causes tubular damage of the convoluted and straight portions of the proximal tubule. Reabsorption of phosphate predominantly occurs in the proximal convoluted tubule. Although the number of patients with idiopathic hypercalciuria was only eight, there were proportionally more patients in this group who received aminoglycosides after a high trough concentration. We are not aware of any long term studies which suggest that renal tubular function may remain altered four to five years after the administration of aminoglycosides. Our findings may be an epiphenomenon and relate to the severity of illness in the neonatal period. However, there was no difference in other indicators of illness severity, including birthweight, gestational age, days in oxygen and days requiring total parenteral nutrition. 
Concentrating capacity in both the study and control group combined was below normal values. ${ }^{17}$ The reduction in concentrating capacity is unlikely to cause any clinical problems. There are limitations to the assessment of renal length by ultrasound scanning. We attempted to minimise these by correlating renal length to height, using one observer who was blind to which group the child belonged. We compared renal length to standards published by Han and Babcock for American children, and used the same scanning methods. ${ }^{21}$ Out of 55 kidneys, eight were on and eight were below the lower limit of the $95 \%$ confidence interval when comparing renal length to the child's height. There are many predisposing factors early in the neonatal period which may cause renal cortical or medullary necrosis. These include renal vein thrombosis, hypoxia, hypotension and nephrotoxic drugs. They are more likely explanations than renal calcification for the reduction in renal size and GFR present in some of our children. Lerner et al reported that renal cortical and medullary necrosis at post mortem examination was associated with congenital heart disease, prematurity, respiratory distress syndrome and bleeding diathesis. ${ }^{39}$

Our results indicated that renal calcification in these children decreased with increasing age. This has also been reported in the study by Downing. ${ }^{12}$ This may explain why the differences in renal function seen in the neonatal period and early childhood, observed in other studies, ${ }^{11} 12$ and considered to be associated with renal calcification, are not present at the age of 4 years.

In summary, the results of this study indicate that children born preterm may have small kidneys and a degree of renal dysfunction. Renal calcification detected in the neonatal period does not seem to be a major predisposing factor to the renal excretion of calcium, concentrating ability, and renal size in these children. The clinical importance and aetiology of these abnormalities of renal function in our patients are unclear.

We thank the Alder Hey Children's Kidney Fund for funding CAJ.

1 Hufnagle KG, Khan SN, Penn D, Cacciarelli A, Williams P. Renal calcifications: a complication of long term frusemide therapy. Pediatrics 1982;70:360-3

2 Ezzeden F, Adelman R, Ahlfors CE. Renal calcification in preterm infants: pathophysiology and long-term sequelae. f Pediatr 1988;113:532-9.

3 Kennney IJ, Aiken CG, Lenney W. Frusemide-induced nephrocalcinosis in very low birth weight infants. Pediat Radiol 1988;18:323-25.

4 Adelman RD, Abern SB, Merten D, Halsted CH. Hypercalciuria and nephrolithiasis - a complication of TPN. Pediat rics 1977;59:473-5.

5 Vilesis RA. Effect of phosphorus intake in TPN infusates in premature neonates. $\mathcal{F}$ Pediatr 1987;110:586-90

6 Malek RS, Kelalis PP. Pediatric nephrolithiasis. f Urol 1975;113:545.

7 Rowe JC, Lazar AM, Condren TB, Adams ND. What is hypercalciuria in VLBW premature infants and what does it mean? Pediatr Res 1990;27:337A.

8 Murphy JL, Mendoza SA. Decreased urinary citrate in premature infants and lung disease. Child Nephrol Uro 1990;10:76-80

9 Hoppe B, Hesse A, Neuhaus T, Fanconi S, Forster I, Blau $\mathrm{N}$, et al. Urinary saturation and nephrocalcinosis in preterm infants. Effect of parenteral nutrition. Arch Di Child 1993;69:299-303.
10 Jacinto JS, Modanlou HD, Crade M, Strauss AA, Bosu SK. Renal calcification in VLBW infants. Pediatrics Renal calcifica
1988;81:31-5.

11 Short A, Cooke RWI. The incidence of renal calcifications in premature infants. Arch Dis Child 1991;66:412-17.

12 Downing GJ, Egelhoff JC, Daily DK, Thomas MK, Alon U. Kidney function in very low birth weight infants with furosemide-related renal calcifications at ages 1 to 2 years. f Pediatr 1992;120:599-604.

13 Myracle MR, McGahan JP, Goetzman BW, Adelman RD. Ultrasound diagnosis of renal calcification in infants on chronic frusemide therapy. $\mathcal{F}$ Clin Ultrasound 1984;14:2817.

14 Pak CYC, Kaplan R, Bone H, Townsend J, Waters O. A simple test for the diagnosis of absorptive, resorptive and renal ple test for the diagnosis of absorptive, resorptive
hypercalciuria. N Engl f Med 1975;292:497-502.

15 Stapleton FB, Noe HN, Jerkins G, Roy III S. Urinary excretion of calcium following an oral calcium loading test in healthy children. Pediatrics 1982;69:594-7.

16 Holland B, Welch AA, Unwin ID, Buss DA, Paul AA, Southgate DAT. McCance and Widdowson's the composition of foods. 5th edn. Cambridge: Cambridge Royal Society of Chemistry/Ministry of Agriculture, Fisheries and Food, 1991.

17 Marild S, Jodal U, Jonasson G, Mengalus L, Odén A, Persson N-G. Reference values for renal concentrating capacity in children by the desmopressin test. Paediatr Nephrol 1992;6:254-7.

18 Stark H, Eisenstein B, Tieder M, Rachmel A, Alpert G. Direct measurement of TP/GFR: a simple and reliable parameter of renal phosphate handling. Nephron parameter of

19 Morris MC, Allanby CW, Toseland P, Haycock GB, Chantler C. Evaluation of a height:plasma creatinine formula in the measurement of glomerular filtration rate. Arch Dis Child 1982;57:611-14

20 Skinner R, Cole M, Pearson ADJ, Keir MJ, Price L, Wyllie $\mathrm{RA}$. Inaccuracy of glomerular filtration rate estimation from height/plasma creatinine ratio. Arch Dis Child 1994;70:387-90.

21 Han BK, Babcock DS. Sonographic measurements and appearance of normal kidneys in children. Am $\mathcal{F}$ Radiol 1985;145:611-16.

22 Shield JPH, Hunt LP, Baum JD, Pennock CA. Screening for diabetic microalbuminuria in routine clinical care: which method? Arch Dis Child 1995;72:524-5.

23 Shaw NJ, Wheeldon J, Brocklebank JT. Indices of intact serum parathyroid hormone and renal excretion of
calcium, phosphate and magnesium. Arch Dis Child calcium, phosph

24 Goldsmith DI, Novello AC. Clinical and laboratory evaluation of renal function. In: Edelman CM, ed. Paediatric Kidney Disease. 2nd edn. London: Little, Brown, 1992, 467.

25 Downing GJ, Egelhoff JC, Daily DK, Alon U. Furosemiderelated renal calcifications in the premature infant. Pediatr Radiol 1991;21:563-5.

26 Shultz PK, Strife JL, Strife CF, McDaniel JD. Hyperechoic renal medullary pyramids in infants and children. Radiology 1991;181:163-7.

27 Hijazi Z, Keller MS, Gaudio KM, Siegel NJ. Transient renal dysfunction of the neonate. Pediatrics $1988 ; 82 ; 929-30$.

28 Kruse K, Kracht U, Kruse U. Reference values for urinary calcium excretion and screening for hypercalciuria in children and adolescents. Eur F Pediatr 1984;143:25-31.

29 Akashi S, Motizuki H. Screening for hypercalciuria. Acta Paediatr fpn 1990;32:701-9.

30 Ghazali S, Barratt TM. Urinary excretion of calcium and magnesium in children. Arch Dis Child 1974;49:97-101.

31 Reusz G, Tulassey T, Szabo A, Tausz I, Miltenyi M. Studies on the urinary calcium excretion in children with haematuria of postglomerular origin: effects of the variation of dietary calcium and sodium intake. Int $\mathcal{F}$ Pediatr Nephrol 1986;7:221-6.

32 Natovitz J, Miller LA, Stapleton FB. Dietary sodium and the diagnosis of hypercalciuria. Pediatr Res 1992;31:331A.

33 Cervera A, Corral MJ, Gomez Campdera FJ, De Lecea AM, Luque A, López Gámez JM. Idiopathic hypercalciuria in children. Acta Paediatr Scand 1987;76:271-8.

34 Voskaki I, Mengreli C, Kipourou K, Vretos C, Sbyrakis S. The diagnosis of hypercalciuria in children. $\mathrm{Br} \mathcal{F}$ Urol 1988;61:385-91.

35 Leman JJ, Adams ND, Gray RW. Urinary calcium excretion in human beings. $N$ Engl 7 Med 1979;301:535-41.

36 Pietschmann F, Breslau NA, Pak CYC. Reduced vertebral density in hypercalciuric nephrolithiasis. $\mathcal{F}$ Bone Min Res 1992;7:1383-8.

37 Broadus AE, Insogna KL, Lang R, Ellison F, Dreyer BE. Evidence for disordered control of 1,25 dihydroxyvitamin $\mathrm{D}$ production in absorptive hypercalciuria. $N$ Engl $\mathcal{7}$ Med 1984;311:73-9.

38 Shen FH, Ivey JL, Sherrard DJ, Nielson RL, Haussler MR, Baylink DJ. Further evidence supporting the phosphate leak hypothesis of idiopathic hypercalciuria. Adv Exp Med Biol 1978;193:217-23.

39 Lerner GR, Kurnetz R, Bernstein J, Chang CH, Fleischmann LE, Gruskin AB. Renal cortical and renal medullary necrosis in the first three months of life. Paediatr Nephrol 1992;6:516-18. 